\title{
The Use of Mobile Technology in Learning English Language
}

\author{
Mohammad Mahdi Mobinizad \\ Towheed Iranian School, Dubai, UAE
}

\begin{abstract}
The mobile phone is present everywhere nowadays and the advent of this technology is transforming the way we communicate and interact with other people as it is considered an integral part of anyone's social life. Recently, this technology has made its way to the educational environments across the globe as a way of learning languages instead of the traditional language learning methods which were tedious and had a monotonous nature for the rising generation. More and more English language apps are being developed, made and posted on AppStore ${ }^{\mathrm{TM}}$ or GooglePlay ${ }^{\mathrm{TM}}$ that can be accessed via the language learners and even English language teachers as well as other educational authorities to be used in the English language classes. Some of these apps are the mobile version of those websites that provide English learning materials for the students as well as other language learners. The said websites have gone one step ahead and have developed separate student edition as well as teacher edition that have caused the English language learning world to undergo massive changes. In this paper, we discuss the mobile-based language learning versus the traditional-based language learning in English language classes.
\end{abstract}

Index Terms - mobile-based learning, traditional-based learning, apps, mobile technology, English language, eLearning (or ELearning), m-Learning, challenges, objectives

\section{INTRODUCTION}

The learning of a language can be included under the two major categories of traditional leaning and e-Learning. ELearning is a broad concept that has its own methods including self-study, video/audio tape, CBTs and WBTs, blended e-Learning, mobile learning, social learning, simulation, and game-based learning. Most of these methods relating to eLearning, especially the mobile-based learning methods, have been born and used from the second half of $20^{\text {th }}$ century up to the present time (Amit K., 2015). But the one that prevails over all the other eLearning methods is the mobilebased language leaning method that has been widely accepted and some of the significant factors which resulted in the acceptance of this method over the other existing methods were its portability, user-friendly interface and humancomputer interaction in some cases relying on the technology used by its developer(s). The sole player in a traditional learning method is the language teacher and some of its methods, including quick answer and full answer, are all teacher-oriented and there is almost no trace of creativity in either of the traditional language learning methods and the students only perceive the teachings, and messages conveyed to them by the teacher only. The latest language teaching approach in today's world is called Communicative Language Teaching (CLT) which is an approach to teaching of second and foreign languages which emphasizes interaction as both the means and the ultimate goal of learning a language (Savignon, 2000). It is also referred to as "Communicative Approach". This latest approach in language teaching (i.e. CLT approach) correlates with eLearning which in turn has been represented in the best widespread form available nowadays, namely mobile learning. This research paper spotlights the characteristics and uses of mobile learning after providing a summary of all the eLearning methods.

Before focusing on mobile learning method itself and comparing it with the traditional learning, eLearning methods are introduced at the first stage (Amit K., 2015):

\section{Methodology}

\section{Self-study}

This is the most common method used nowadays in which all the necessary required learning materials are provided on the website and the login details are given to the language learners. In some cases, a 24/7 instructor is also available to help the language learners any time that they may encounter and experience problems either with the website itself or the learning materials and steps that should be taken to finish their online assignments.

\section{Video/audio tape}

This is the second method that is mostly used for creating demo videos that can result in training the language learners and it can also help the language learners know the basics of the language they are striving to be successful at by watching or listening.

\section{CBT (Computer-Based Trainings) and WBTs (Web-Based Trainings)}

E-courses are given and made in either of the above methods or even a combination of them that can be more useful for the e-course learners. Both of these courses utilize the Internet as their primary platform. Since these courses are 
self-paced and the language learners have no interaction with each other and also their trainer/instructor, they can work well with the language learners who are self-motivated to learn many new skills.

Blended eLearning/Instructor-led (ILT)

This method is taken where the classroom exercises and interactions are required. This method is a combination of the traditional method of teaching with the eLearning method and is appropriate for short e-courses in which a background of the lesson is given to the language learners to prepare them before entering the classroom.

\section{Mobile learning / Mobile-based learning}

The most important advantage of this method over the other eLearning methods is the availability, portability, and the affordability of mobile devices which has given the way for more and more learning materials to be produced in the mobile-based learning or mobile learning format. However, some other aspects of mobile learning that can be taken into consideration are its screen size, capacity, and Internet connectivity.

When the language learning materials are delivered via mobile phones, the costs of production of such materials as well as the time taken to prepare them are reduced remarkably.

\section{Social learning}

In this method, the learning materials are also delivered via the mobile phones in the same way as the mobile learning method, but the social media apps play the primary role in this method. The impact of social media in the twenty first century is unavoidable and more and more educational institutions are realizing this fact by investing funds in this field of technology. They also encourage their language learners and even teachers to share and discuss their problems, queries, experiences, etc. on these social platforms. This method is already taken by some other English language teachers who take private tuition classes or even some freelance language teachers.

A good example of this kind can be the Telegram ${ }^{\mathrm{TM}}$ channel of Dr. Iman Pandi that is called "Vocab coding" where the number of the people who are joining this Telegram ${ }^{\mathrm{TM}}$ channel is on the increase in Iran.

\section{Simulation}

Simulation eLearning is a very interactive method and is dependent upon graphics, video and audio. There are also custom simulations videos or games that include 3D components.

\section{Game-based learning}

The most powerful tools in learning a language which are considered to be fun by all the people are video games. The term "gamification" is used nowadays as designing an activity such as learning, solving a problem, etc. Gamification can be a very effective tool for young language learners and help them develop their language knowledge and skills while keeping them entertained at the same time.

Choosing the right eLearning methods totally depends on factors such as the availability, expenses, language learners' characteristics, and so many other things that are associated with eLearning methods (Amit K., 2015).

\section{Mobile Learning}

The use of mobile devices in English language classes has led to revolutionary changes in the way the language learners learn the English language. Mobile learning is a type of learning that takes place with the help of mobile devices (Kukulska-Hulme\& Shield, 2008).

While at the beginning, mobile learning used to focus on the role of mobile phones in education, in the twenty first century the mobile learning is associated with the mobility of the users or language learners in an English classroom.

Mobile learning has certain benefits for language classes as well and allows language teachers to offer access to authentic content, communicative language practice, and task completion (Chinnery, 2006). While the effect of some mobile phone affordances such as Short Message Service (SMS), voice-messaging, cameras, video-recording and internet access have spawned studies (e.g., Thornton \& Houser, 2005; Jee,2011), "few studies have investigated students' personal use of mobile apps for learning and the learning benefits" (Steel, 2012, p. 1).

Mobile learning can be defined as "any educational provision where the sole or dominant technologies are handheld or palmtop devices" (Traxler, 2005). A mobile device is "any device that is small, autonomous, and obtrusive enough to accompany us in every moment" (Trifanova \& Ronechetti, 2003, p.3). In accordance with the developmental history of mobile learning (Sharples, 2006) three aspects can be specified for this type of learning (El-Hussein \& Cronje, 2010):

- Mobility of technology

- Mobility of learning

- Mobility of learner

Mobility of technology focuses on examining the possibility of using portable devices such as mobile phones, laptops, and tablets for educational purposes. The focus of mobility on learning is on the extensive use of mobile devices for learning inside and outside the class.

The third aspect focuses on "the mobility of the learner, the design or the appropriation of learning spaces and on informal learning and lifelong learning" (Pachler, Bachmair, \& Cook, 2010, p. 41)

The development of mobile phones in the recent years from simple phones to smart-phones, which can serve as a mini-computer for transferring all kinds of data, has made mobile phones efficient learning tools. Klopfer and Squire (2008) describe the affordances of mobile phones as:

- Portability: can take the computer to different sites and move around within a location;

- Social interactivity: can exchange data and collaborate with other people face to face; 
- Context sensitivity: can gather data unique to the current location, environment, and time, including both real and simulated data;

- Connectivity: can connect handhelds to data collection devices, other handhelds, and to a common network that creates a true shared environment;

- Individuality: can provide unique scaffolding that is customized to the individual's path of investigation (cited in Squire \& /Dikkers, 2012, p. 447);

Mobile devices are effective tools for language learning in general terms (e.g., Rosell- Aguilar, 2007; Fallahkhair, Pemberton, \& Griffiths, 2007). They have positive effect on the development of language skills (e.g., Chen \& Chang, 2011; Chang \& Hsu, 2011), heighten learners' language learning attitudes and motivation (e.g., Huang, Huang, Huang, \& Lin, 2012), and support learner interaction, collaboration, and co-construction of knowledge (Joseph \& Uther, 2009).

\section{DISCUSSION}

\section{Mobile Learning Characteristics}

According to the researches that have been conducted on characteristics of this kind of eLearning, a number of characteristics has been described for mobile learning. Some of the most important ones are provided below (AlAhmadi, 2013):

1. Portability and mobility: Device portability relies on some physical features of the device such as size, weight, and the number of latest technologies applications provided in the construction of the device.

a) The language learners can access the saved information anytime at any place including their English language class.

b) When the data and information are stored in mobile phones, they are portable and moveable.

2. Wireless networking: This characteristic makes the process of learning vital and flexible because most of problems related to Internet connection can be avoided.

3. Interactivity: mobile learning is related to three aspects:

a) The educational cognitive environment: By means of mobile learning, even distant language learners who are not in the same area or geographical region can interact with the language teacher, physical and virtual environment.

b) Language learners: The mobile learning is considered as an interactive procedure because in this procedure the language learners are the ones who direct the process of learning. They are not like passive language learners in traditional language learning class, who just wait for the language teacher to provide them with the necessary data and information. Instead, they are independent and create their data themselves.

c) Skillful aspect: This aspect deals with using the latest technologies, apps and other language tools which make the English language learners capable of interaction with each other. A number of these technologies include language learning apps, designated channels for learning any language on the social media app channels including WhatsApp ${ }^{\mathrm{TM}}$, Telegram $^{\mathrm{TM}}$, Viber ${ }^{\mathrm{TM}}$, etc.

4. Unlimited Accessibility: In mobile learning, you have access to a wide range of learning materials and resources from anywhere at any time.

5. Privacy: This does not mean that information and data cannot be shared with other language learners or students, but it means that you may have access the data you want independently from other learners.

6. Spontaneity: The information and data provided for the language learners in mobile learning are not planned in advance and are more flexible.

7. Immediacy: This characteristic is always associated with mobile learning. It means we need quick answers for specific queries such as definitions, formula, or equations.

8. Significant high quality files: All the data delivered via mobile devices are characterized with such kinds of files and the said files can be in the form of images, videos and diagrams.

9. Combination of two learning methods: Mobile learning is a combination of two learning methods which are eLearning and distance learning.

10. Availability: This characteristic was the most important factor which led to the widespread use and development of mobile learning among all groups of language learners because people with different economic states or budget are capable of affording a mobile device. Without the availability of mobile technology, it is impossible to consider mobile learning as a language learning option for learning a language such as English (Al-Ahmadi, 2013).

As it is can be seen so far, the mobile device ownership is increasing across the globe and there has been a lot of discussions and researches about the benefits of using mobiles in language learning.

\section{ANALYSIS}

\section{Uses of Mobile in the Classroom}

1. Use of audio recording feature: Lecturers can make use of this feature built into most smartphones in order to provide personal and quality feedback to all the students. The recent researches have proved the interest of the language learners in it. 
2. Live pooling tools: Most of the said tools are free of charge and used to determine what the students or language learners already know and what should be focused on by them. These tools can also provide the strength and weakness of those language topics in which the students are week and need more practice to master those topics.

3. Creating of videos: Rather than asking the language learners to write a long essay on a topic, the language learners can be asked to create a video file or even an audio recording of what they had researched about.

4. Chat and other online discussion forums: To create an online discussion forum to encourage class participation on content topics, language learners can utilize the chat features of mobile phones.

5. Use of Quick Response (QR) Codes: The uses of these quick response (QR) codes are on the increase nowadays and are regarded as another great way to use mobile technology in the classroom. The language learners are capable of chatting or discussing together either in the presence or absence of their teacher.

A research recently conducted at the University of KwaZulu-Natal revealed, concluded that $92 \%$ of the students agree it is easier to use their mobile device to improve the access to the information. The students will be capable to find whatever they need at the right time whether it is general information on the Internet or it is the information related to their English language course.

\section{Efficiency versus Effectiveness}

Before we proceed with continuing the mobile learning topic, there is a need to differentiate between efficiency and effectiveness when we discuss on mobile learning technology. Efficiency in mobile learning mainly refers to the time taken to do something, whereas effectiveness is the level of results required from the actions of the students or language learners. Efficiency deals with achieving something with the least possible resources in the least possible time. The development of mobile technology over the years has helped all the people who are engaged in the education including the language teachers and language learners to achieve this. The powerful features of the mobile technology can be creatively used to make the language learning work effective in order to acquire high results and the language learners are encouraged to add the mobile technology to make the language learning more efficient by preparing plans for creative use of mobile learning in the English language classes (Amit K., 2015).

The English language learning classes or in general, the language learning classes can be more effective by using mobile devices. As all of us has experienced in part of our educational life in the past, the use of mobile phones in the classes were prohibited strictly. However, the remarkable changes happened in the manufacture of these portable devices that changed them from simple devices for daily communication to smartphones which can carry out and handle a large number of the people's daily tasks which was a major step ahead to eliminate these obstacles in using mobile technology in the classes and encourage the educational authorities across the globe to utilize this technology more effectively to benefit in their classes, especially English language learning classes.

Some of the best ways that the mobile devices can be used in the English language classes as an extra tool of learning are listed below (Amit K., 2015):

\section{Look for next class topics / new topics}

This is one of the basic things of learning and it is always better for the language learners to be familiar with the topic that is going to be discusses in their next language class and mobile devices are the tools which make this possible for the language learners.

The teacher can upload the learning materials for the next class topic or even the existing topic in the form of videos, presentation slides, PDF documents and the language learners or students can easily have access to those files at any time through a simple login.

\section{Pre-learning assessments and post-learning assessments}

It is predicted that $70 \%$ of professionals will do some work from their own, personal smart phones or tablets by 2018(Gartner).

Pre-learning and post-learning assessments are the best option available for a language teacher to identify how much of the content or learning materials have sunk into the minds of their students or language learners.

Conducting these assessments before the beginning of learning a topic on a mobile device can help understand the caveats as well as identify the amount of leaning on that particular topic that has been absorbed by the students or language learners.

But the results of the assessments received after the learning procedure (i.e. post-learning assessments) can be compare with the pre-learning assessments to measure the learning analytics and taking the necessary steps required to clear the learning gaps existing.

Both of these assessments can have a wide range of interactive questions that can be answered over the mobile platform and all or some of these questions can even be selected by the language teacher as part of the language learners' classwork or teamwork.

\section{Attendance tracking}

This is a way to find out how each student is doing in the language class and to understand the level of participation of the students attending the language class which is a crucial thing for the language teacher. For example, the language teacher can arrange for and add a QR (quick response) code at the time of creating a mobile course for the language learners. If the mobile course is composed of 8 learning modules or 8 learning chapters, the language teacher can add a QR code for each of the said modules or chapters. 
A copy of the same QR code relating a learning module can be placed anywhere inside the class and the students who attend the class are requested to scan that QR code via their mobile phones in order to have access to all the activities and exercises of that module or chapter and the person who does not scan the code cannot have access to the learning materials of that particular module or chapter. This is considered a paper free and hassle free procedure to track the attendance of a language learner in a language learning session of a language class.

Once the classroom is over, the language learner can sign in once again and refresh whatever was being taught in the classroom through content for revision available on his mobile phone anytime at any place.

\section{Feedback after learning}

The level of satisfaction of the course can be shown at this stage and it shows how the learning was taken by the language learners. This feedback can be about anything including the content, the learning environment, the language learner himself and the overall aspects of whatever was being taught. The feedback can be performed real time or through a list of questions about the whole language learning program. These feedbacks either negative or positive are of high importance for the language teachers for adopting new teaching strategies and approaches as well as the educational authorities in modifying and improving the educational policies in the future.

\section{Tracking}

The other advantage of using mobile devices in the procedure of learning a foreign language such as English is that this technology enables the language teachers to capture the learning journey of their students or language teachers in great detail. The detailed reports generated in this way can be both at individual and cumulative levels (Bhattacharyya, 2016).

Both the performance and participation levels of the language learners can be tracked and monitored strictly via visually enriching reports such as bar charts, pie charts, graph charts, block charts, and so many kinds of charts or tables. This kind of strict monitoring and tracking can provide so much information before the eyes of the language learners. They can notice the strengths and weaknesses of their language learners based on their gender and evaluate their capabilities and talents they may have in a particular language skill(s).

I hereby provide you two examples of my own teaching experience at Towheed International Iranian School in Dubai, UAE. These examples can show you how a teacher can track and monitor his students' language learning skills and help them improve their strengths and eradicate their weaknesses they all encounter in learning a new language.

In our school, we usually use two separate websites for language teaching. One is called "MyELT" that is used with National Geographic English Language Books Series and the other one is called "IXL" which is a digital platform for providing activities and exercises in the area of language arts, math, social studies and science where we hereby focus on the language arts section of this digital platform.

The official website for "MyELT" is http://myelt.heinle.com where the students can have access to the website trough their own login details and proceed with doing the exercises assigned by their teachers within a time period locked by the language teacher. It means that they cannot do any more exercises if their time period is expired.

The teacher can also assign different types of exercises to different students based on their language learning capabilities, especially if there are any SEN (Special Student Needs) students in your language class. Afterwards, the language teacher can track his students' level of participation and performance in different exercises assigned to them in a chart I have provided for you in the following page.

A photo of the cover page of the book whose either app or website is used by my English language students is shown as well.

The next page chart provides the performance and participation of students in language classes in the girls' section of Towheed International Iranian School and expresses doing the exercises of Unit One of National Geographic English Language Series Book No.3.

This unit consists of the following activities:

- Clear and precise words

- Pronoun references

- Unity

- Sequencing information

- Transitional words and phrases

- vocabulary

- Editing

- writing 


\begin{tabular}{|c|c|c|c|c|c|}
\hline Student $\boldsymbol{\Delta}$ & Total $\mathbf{r}$ & Unit 1/ I...ction to Paragraphs / Editing & Unit 1/1...entifying Unrelated Sentences & Unit 1 / I...on to Paragraphs / Noun Forms & Unit 1/ 1...electin \\
\hline @Alcbari, Ghazal & $73.82 \%$ & $70 \%$ & $50 \%$ & $30 \%$ & $50 \%$ \\
\hline Qbarzegar, fatemeh & $98.95 \%$ & $80 \%$ & $100 \%$ & $100 \%$ & $100 \%$ \\
\hline Qebrahimzadeh, sadaf & $80.63 \%$ & $60 \%$ & $75 \%$ & $100 \%$ & $90 \%$ \\
\hline Qjalali, Negin & $97.91 \%$ & $100 \%$ & $100 \%$ & $100 \%$ & $100 \%$ \\
\hline ■jalitil, hosna & $31.41 \%$ & 096 & $0 \%$ & $0 \%$ & 096 \\
\hline Qjoukar, leila & $42.93 \%$ & $50 \%$ & $50 \%$ & $80 \%$ & $90 \%$ \\
\hline Qkhajavi, hedieh & $92.15 \%$ & $70 \%$ & $75 \%$ & $100 \%$ & $90 \%$ \\
\hline Qmzn, zahra & $83.7 \%$ & $90 \%$ & $100 \%$ & $100 \%$ & $60 \%$ \\
\hline Qrafiei, maryam & $29.84 \%$ & $0 \%$ & $0 \%$ & $0 \%$ & $0 \%$ \\
\hline Qramzi, zahra & $100 \%$ & $100 \%$ & $100 \%$ & $100 \%$ & $100 \%$ \\
\hline QSaidian, Farnaz & $100 \%$ & $100 \%$ & $100 \%$ & $100 \%$ & $100 \%$ \\
\hline Q shafiee, zahra & $92.15 \%$ & $100 \%$ & $100 \%$ & $80 \%$ & $80 \%$ \\
\hline Q Shekari, Shiva & $97.38 \%$ & $100 \%$ & $100 \%$ & $100 \%$ & $100 \%$ \\
\hline Qsorbi, manyam & $72.25 \%$ & $70 \%$ & $50 \%$ & $70 \%$ & $80 \%$ \\
\hline \multicolumn{6}{|c|}{+1} \\
\hline
\end{tabular}

Chart 1: Students' performance and participation in doing online practices

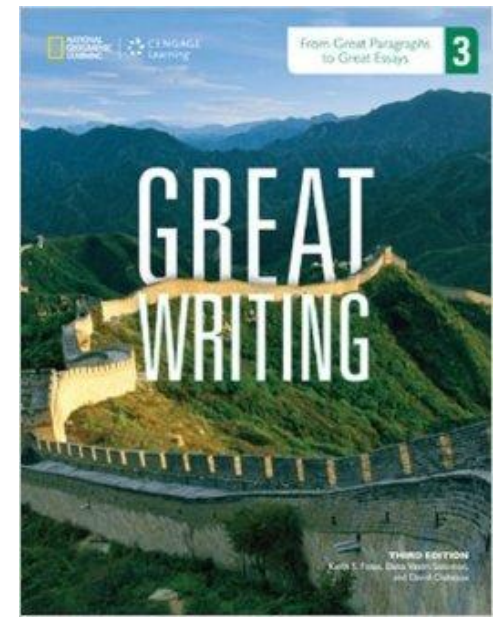

As a language teacher, you can easily track their performance in doing the exercises of Unit One in the said book in the form of a percentage and a percentage average of their overall performance for each chapter or unit is given separately.

Another official website introduced above is "IXL" website which is a digital educational platform and its app version is also available at Apple $\odot$ AppStore ${ }^{\mathrm{TM}}$ for mobile learning in English language classes and this is the key of success for this website that made it one of the popular educational digital platforms among the UAE schools including Towheed International Iranian School and is widely used by the English language learners. IXL official website is given below:

http://www.ixl.com

Because our school has purchased the annual subscription for this website and we are a member school of their digital educational platforms, our language teachers usually sign in the said website through the following link:

http://www.ixl.com/signin/towheed

Same as the "MyELT", I hereby provide you the analytics report of the same class students in general and some of my particular students in that class in great detail.

A sample screenshot of the website welcome page is shown below: 


\section{IXe.}

\section{Towheed International School}

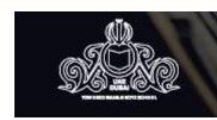

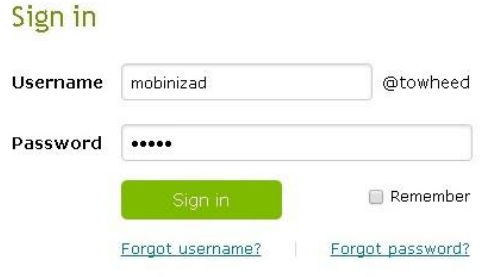

Teachers, have an activation key? Set up your account

Not from Towheed International School?
Welcome to IXL!

IXL is a comprehensive, standards-aligned math and

language arts practice program offering unlimited problems in thousands of skills. One of the best things ab
that you may use it from school and from home!

Before you start, be sure to sign in to your IXL account! Enter your username and password on this page and click "Sign in." If you do not know your username or password please ask your teacher. And reme user to bookmark

After signing in, click on your level - to select skills to practice. You may place your mouse over any skill to see a sample question. Or, click the Awards tab to begin
conquering challenges and uncovering prizes!

IXL - Practice and excell

Learn more about IXL $\gg$

After you login the IXL website, you can see the exercises are listed according to different levels from Level A up to Level N. Level A is designated for KG1 students or language learners and Level N is designed for Grade 12 students or language learners who will graduate from the high school. The content of the exercises for each level of students is defined according to their abilities and appropriateness for their age. For Example, KG1 students are more fun-driven than content-driven.

This website contains many tracking tools for the language learner to understand the progress of the students in English language. The first tab is "Dashboard" tab that is shown below:

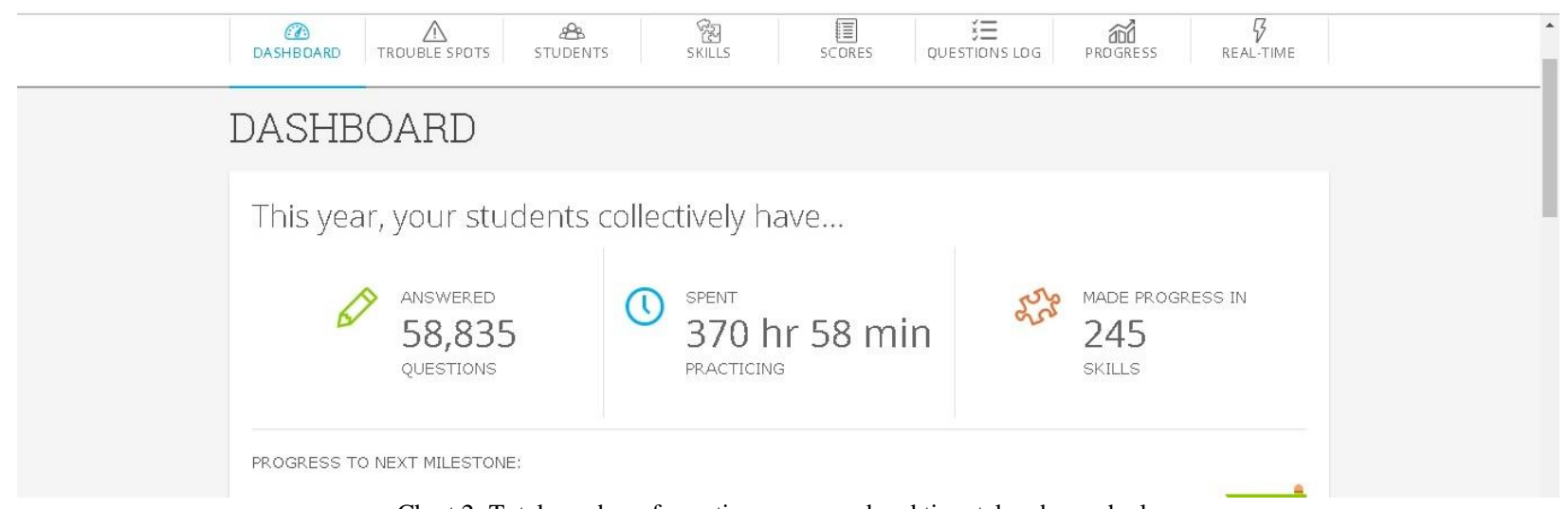

Chart 2: Total number of questions answered and time taken by each class

This tab tracks information such as the total number of questions answered, the time spent by them and their progress in language learning skills.

The second tab is called "Trouble Spots" whose screenshot is provided below:

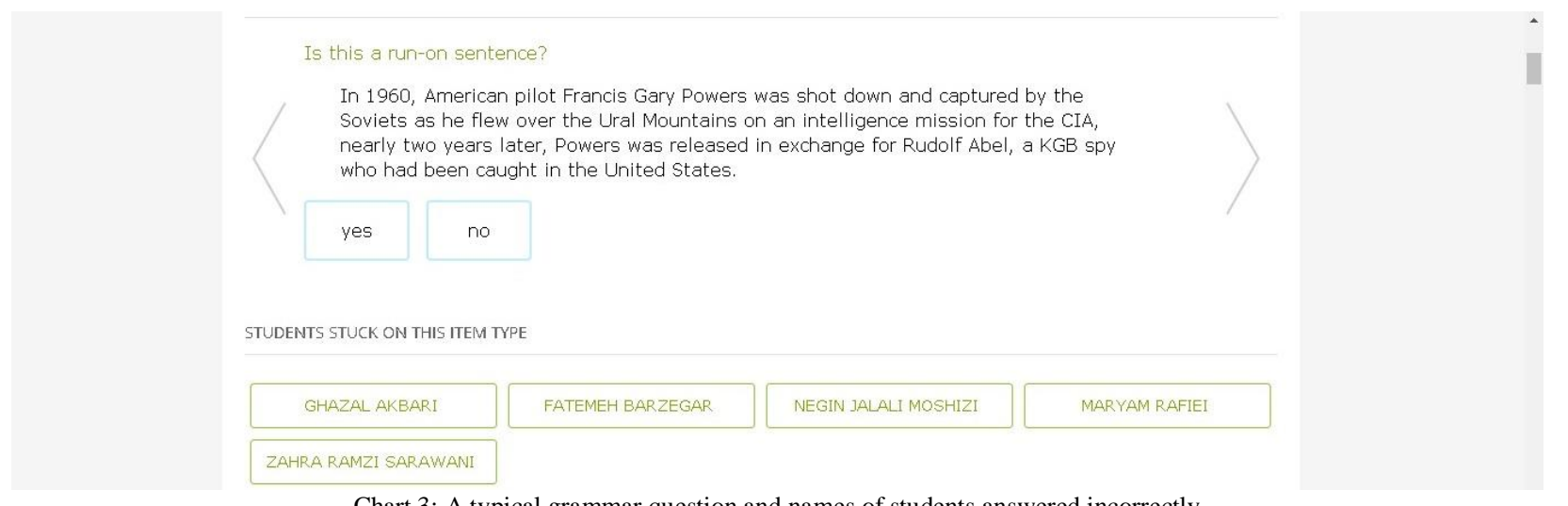

Chart 3: A typical grammar question and names of students answered incorrectly

The tab shows the question or questions that the language learners were unable to answer or even missed and the name of those language learners are provided after the question itself in green boxes. 
The third tab is "Students" tab which shows the amount work practice by the student at school as well as the activities done by the students at home or whenever the student was at home or anywhere out of the school and had access to his mobile device.

The daily practice of each language learner is shown in a separate bar chart same as the typical bar chart provided in the next page for one of my students in the said class and it can be easily recognized based on their color. The green color shows the practice was done at school and the blue color shows the practice was done at home or anywhere else where the mobile devices were within the access of the language learners. Their category practice is also represented in different colors and in a circular shape.

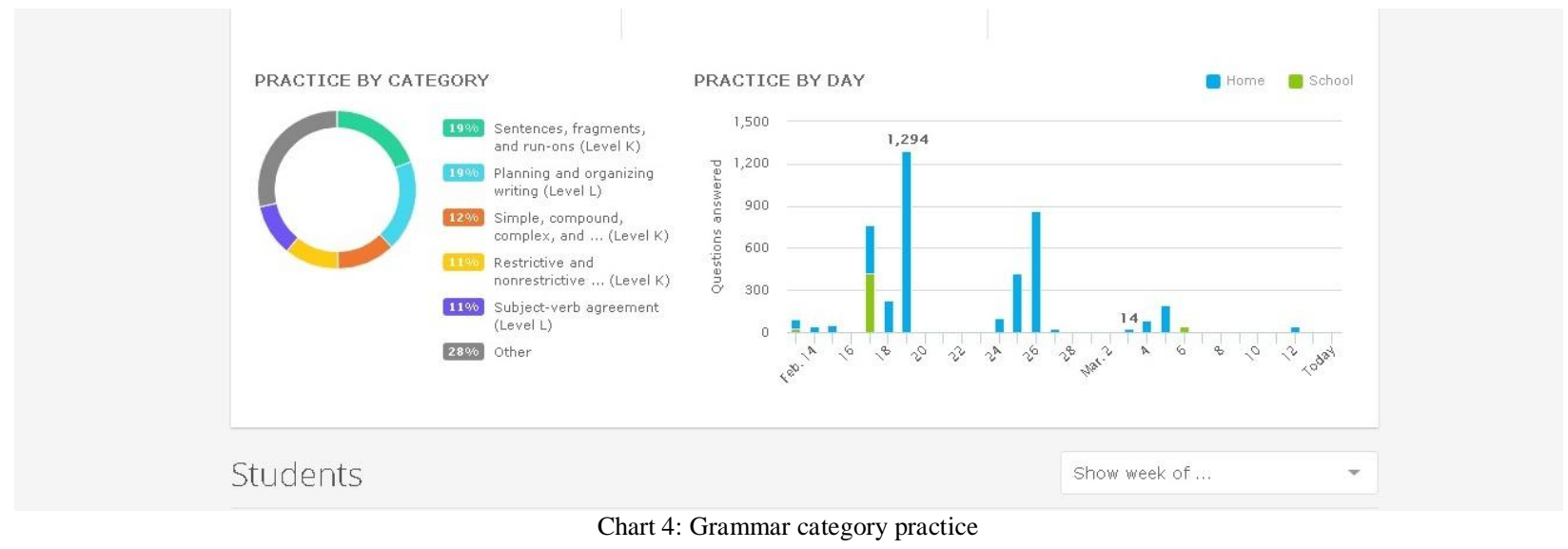

The "Skills" tab is the following tab which evaluates the language learners' skills in doing the modules they were assigned plus some other useful information such as the number of students who practiced that particular module, the questions answered and the time sent by them.

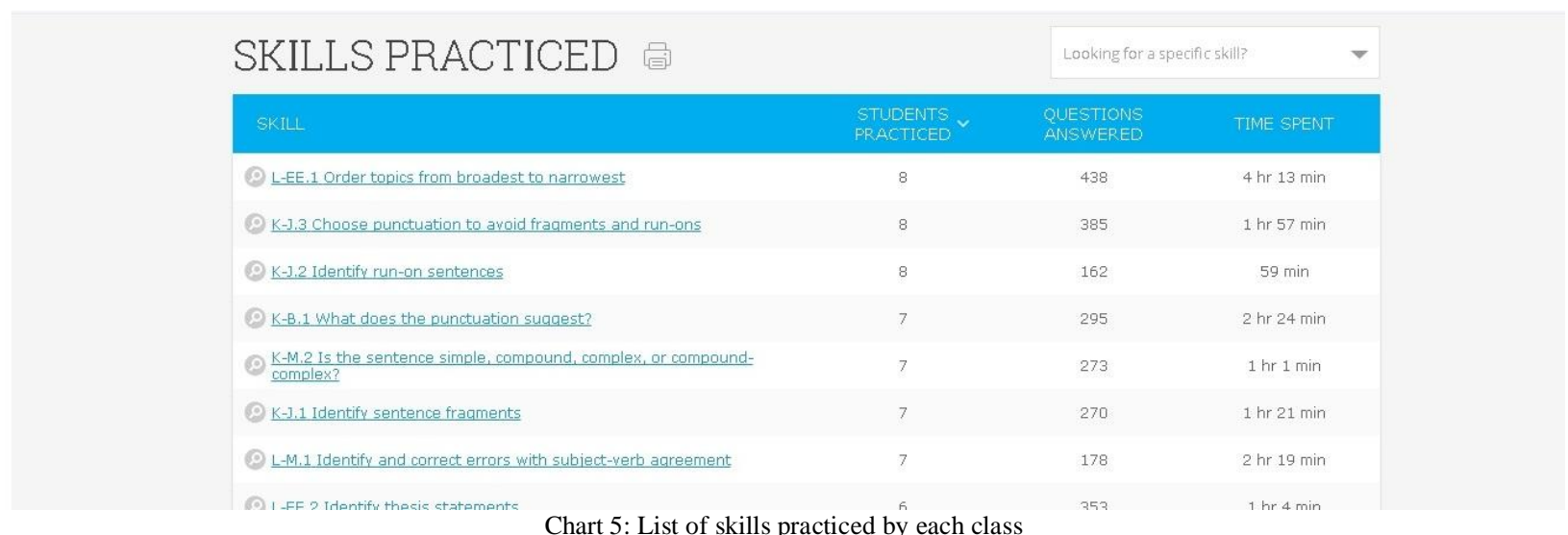

The fifth tab is called "Scores" tab and provides a more detailed analysis among the students of the same class in answering various modules of a topic in the form of a grid.

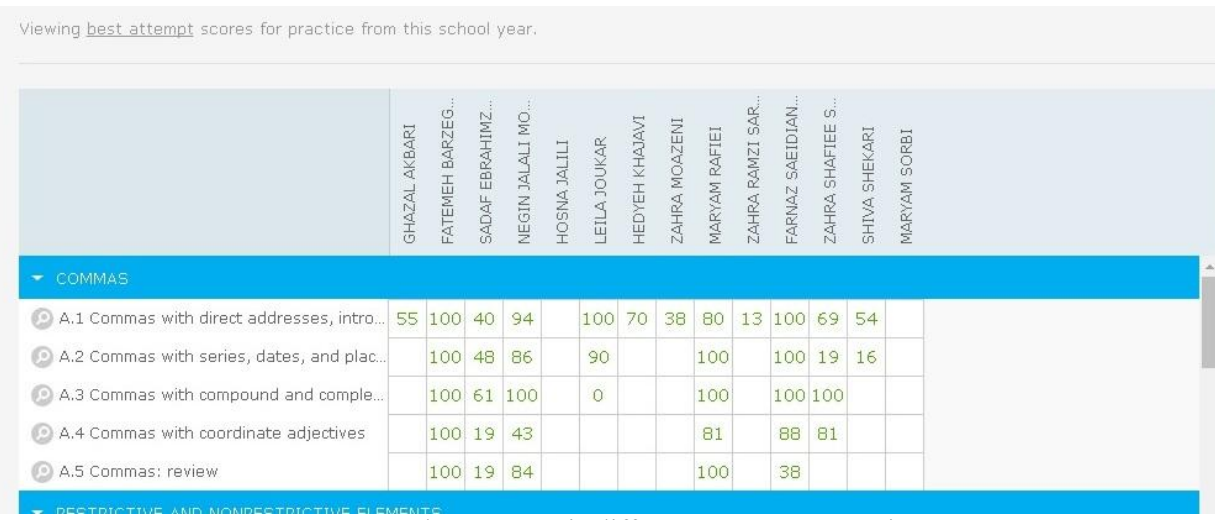

Chart 6: Students' scores in different grammar categories 
The sixth tab is "Questions Log" and includes information such as current smart score, the number of questions answered and the time spent separately and in the form of a chart as well. This information is available for each of the students in a class and can be of great potential for both the English language learners and the English language teacher.

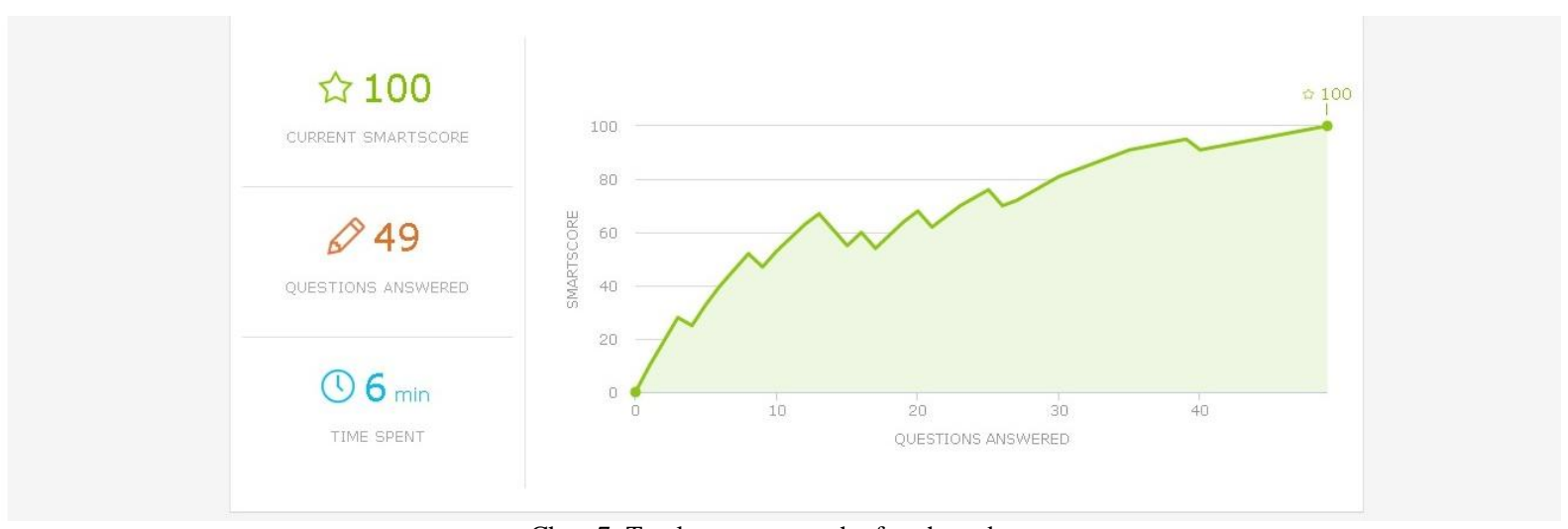

Chart 7: Total progress graph of each student

The seventh tab is "Progress" tab and is a sign of the amount of progress and improvement of any of the English language class students in a particular area of English such as language arts, grammar or even writing mechanics.

The language teacher can also track the performance speed of the student in answering each of the questions and whenever there is no logical connection between the time spent by the student and the related questions answered by the same person, or even when there is a long delay in answering the questions, I can conclude that the student just repeats himself and does not know how to find out the answer.

This also means that the student(s) do not master some topics completely and they have a lack of comprehensive information in that language skill.

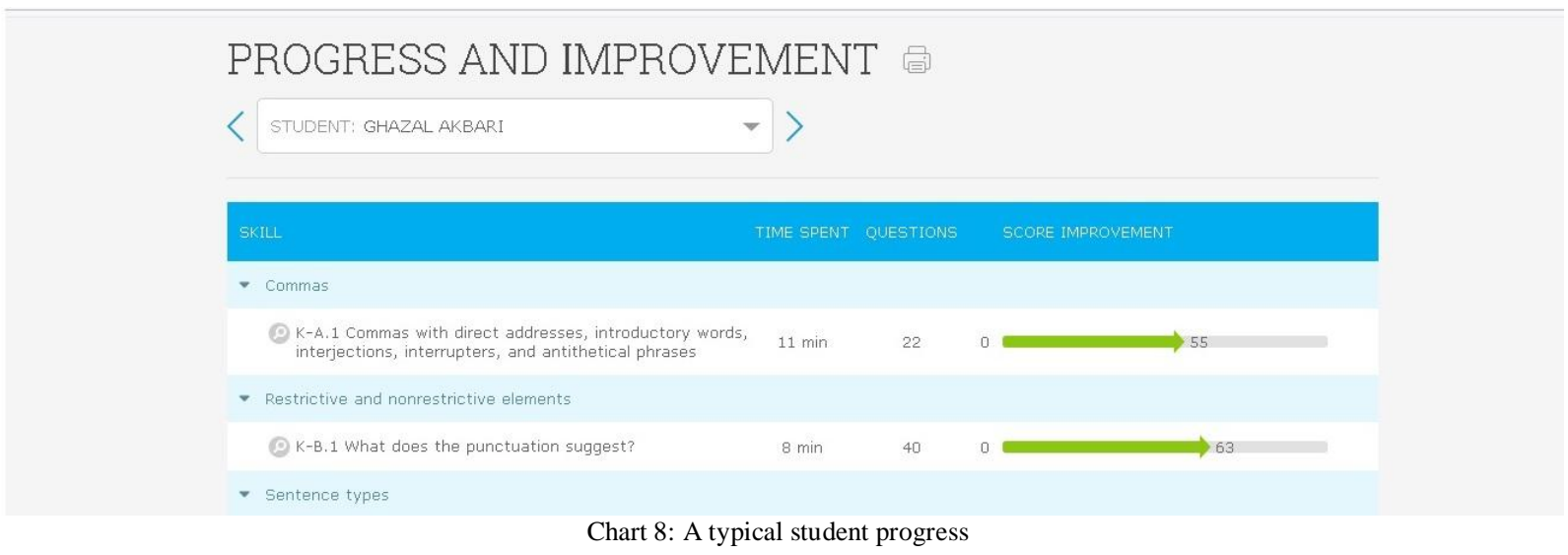

The last tab is "Real-time" tab and is always referred to as a student activity wall where everything is marked and registered over this wall and each language learner or student has his own activity wall.

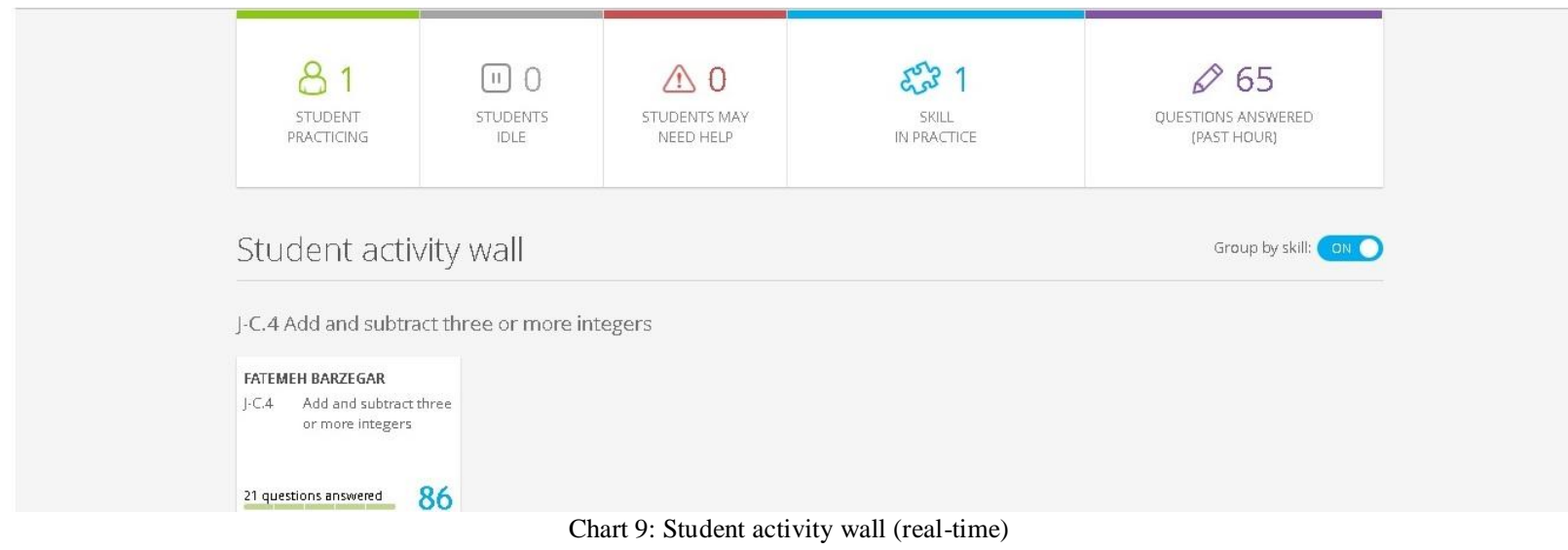

Utilizing websites such as the one I use at Towheed International Iranian School in Dubai is a typical tracking website whose app is installed on the students' mobile devices in the English language classes and is a practical way of 
tracking your language students before or after entering the class and encourage their tendency in participation in classes more than before.

This can be regarded as a useful interaction of education and technology in the current century which benefits both the English language teachers and the English language learners and will result in more progressive learning processes in the upcoming years. the preferences for mobile learning is on the increase with time and using their potential power to make the English language learning more exciting and interesting can reward the English language learners and their lecturers or teachers.

You have learned so far that a language teacher can make the most advantage of a language learning class by embracing the mobile learning in his or her language classes or even the live events of his or her classroom. The mobile learning technology in a language class can raise the engagement and participation of in a language learning class. I hereby introduce 5 easy tips that can be taken by a language teacher to build the mobile learning into his or her classroom events or teachings and instructions (Davis, 2013).

\section{Poll or quiz learners in real time}

Using a service like "Poll Anywhere" accompanied with the learners' mobile phones, you can set up a poll or quiz in order to track the instant messages sent via text, twitter, or a web browser.

At first, the language learner can prepare so sort of fun language-related activity to get the attention of the language learners and make them familiar with this technology, and then continue to engage them throughout the class.

\section{Leverage an online learning space related to the event}

An online learning space (for example, a members-only group on Whatsapp ${ }^{\mathrm{TM}}$ or LinkedIn $^{\mathrm{TM}}$ ) offers tools for interacting with other language learners during a language learning session and the learners would be able to use their cell phones to log in to their online learning portal during the language training. They can also benefit the online learning portal by recalling and refreshing on what they learned for on-demand learning

\section{Watch a video online}

According to the policies defined for mobile learning in a language learning class by the instructional designers of classroom materials and educational facilitators, the access to a wide range of comprehensive resources including the multimedia files can live up any language learning experience.

You can create a video channel relating to your language learning class on "YouTube" website and upload weekly videos for your students to watch, especially whenever you are on long vacation or you have a sick leave and cannot attend the language class physically. It can even be a pre-learning video which sounds necessary for all the language learners of a particular language class before taking part in the next language learning session. Depending on the nature of the video, language learners can reference it later for on-demand mobile learning.

\section{Build Internet-related activities}

This is a useful adjunct to the real language learning classes. An easy way to do such kinds of activities is to ask learners to research online information related to the topic at hand. These activities can be assigned individually or as a group depending on the size and structure of language classroom.

\section{Use voice messages}

By leaving a voice message on a language learning class group, all the students invited in that group-whose administrator is the language teacher of the said class- can receive all the necessary instructions or directions they need to answer their activities during the class time or even when the teacher is out of reach and is not present in the language class. For example, the message can provide clues that learners need to address a series of questions as part of an activity (Davis, 2013).

"The inclusion of mobile technologies in a language learning class can indeed increase the impact of learning, but it can also have its own concerns for the language teachers which will be discussed in the following chapters".

\section{Results}

\section{Mobile learning concerns in a language class}

The concerns involved in mobile learning range from fears of distraction to personal lack of knowledge on how technology works and some other concerns that may threaten the language learners' potential capabilities which seem to be of less degree of importance in relation to the advantages that this technology brings with itself to make the language learners more active than the traditional language learning classes.

Some of these common concerns are listed below (Amit K., 2015):

1. The technology supersedes the language learner's knowledge.

If the language learner feels that his technological literacy is lower than his students, this may bring in a loss of confidence in handling new technology for learning. In these cases, the best way for a language learner is to update his knowledge of the recent technologies or even software released to the market and study the software tutorials in order to take and gain confidence in handling them. The language teacher can understand and master the utility of the available apps and choose the right ones for their classroom.

Then he can also answer the learners' queries on how to use it and afterwards, the language learners can follow up their language teacher's instructions for using that app on their cell phones so that the language teacher not only gains confidence but also feels that he or she is one step ahead of his students or language learners. 


\section{The mobile devices are considered as distracting tools by language teachers.}

The language teachers may have such opinions because all of our daily lives are saturated with mobile phones, but there are ways that can help the language teachers to harness their students' appeal for mobile technology into classroom training.

The popularity of the mobile phones should be an opportunity for language teachers to embrace and channel the interests of their students by integrating mobile devices into classroom learning. So it is the best to make the most of this technology and avoid conflict with learners over the prohibition of their favorite device when getting students involved in the lesson by allowing use of the technology that would otherwise be a distraction.

3. The language teachers sometimes cannot tie mobile learning into the language learning class.

In fact, cell phones were not invented for learning, but there are many features embedded in smart phones that made them as the best practical tool to be utilized in a language classroom. Language learners or instructors can prepare specific assignments for language learners to complete, and learners can carry them out using their mobile devices. Mobile learning apps are integral to a language lesson and become second nature for language teachers and students to use. And the language learners should be aware that some mobile apps designed for language learning programs or classes will work better for certain teaching styles than others. In the end, no one can deny that mobile devices are here to stay and the number of the mobile apps is increasing with each passing day. Most language learners or lecturers agree that student engagement increases and learning outcomes are achieved better when language classroom lessons are run by mobile technology as part of the language learning procedure.

Mobile learning objectives

\section{Encourage 'anywhere, anytime' learning}

Mobile devices allow students to collect, access, and process data in and out of the classroom, but our focus in this paper is on in-class mobile learning. One of the objectives here is to encourage learning in a real-world context.

\section{Reach underserved children}

Getting access to the children from economically disadvantaged communities and those from the developing countries is another objective that can be met with the help of these digital handheld devices.

\section{Improve the social interactions}

If you want to be a successful person in the $21^{\text {st }}$ century, it is necessary to promote your communication via the help of mobile devices.

\section{Fit with learning environments}

Mobile devices can help overcome many of the challenges associated with other technologies in various learning environments.

\section{Enable a customized learning experience}

Instruction can be adaptable according to the needs of each language learner and this is what that can be individualized through mobile learning (Source: $\underline{\text { htp://Mobl21.com). }}$ ).

\section{Mobile learning challenges}

\section{Negative aspects of mobile learning}

The potential for distraction or unethical behavior, physical health concerns, and data privacy issues are some of the common disadvantages related to mobile learning.

\section{Cultural norms and attitudes}

A 2008 study done by the Joan Ganz Cooney center in collaboration with Common Sense Media found that most teachers see cell phones as distractions and feel that they have no place in school.

\section{No mobile theory of learning}

Up to now, no widely accepted learning theory for mobile learning has been defined and established among the educational authorities or even among the English language learners themselves.

\section{Differentiated access and technology}

The mobile technologies represent a challenge for language teachers as well as the language learners or students who wish to accelerate academic outcomes.

\section{Limiting physical attributes}

Small screen size and limited battery life are two major physical aspects of mobile phones that prevent an optimal learning experience. These existing problems may be eliminated in the upcoming years (Source: http://Mobl21.com).

I hereby draw your attention to the following table made and prepared by "mobl21" website. (Source: http://Mobl21.com). This chart compares e-Learning with m-Learning (or mobile learning). Before you proceed with the chart given below, keep in mind that e-Learning can be real-time or self-paced but on the contrary, mobile learning is self-paced ad informal in its presentation.

\begin{tabular}{|l|l|}
\hline e-learning & mobile learning \\
\hline lecture in classroom or Internet labs & learning anywhere, anytime \\
\hline e-mail to e-mail & instantaneous messaging \\
\hline private location & no geographic boundaries \\
\hline travel time to reach to Internet site & no travel time with wireless Internet connectivity \\
\hline
\end{tabular}




\section{CONCLUSION}

The fact that technology has entered our classrooms and is here to stay is undeniable. What is left is finding the best possible way to navigate through the sea of pros and cons finding the best possible solutions for your students and their needs (Sarah Green, 2015). As you read this paper, you noticed that no fixed theory has been established in the field of mobile learning but this technology is making progress on its way towards the next generation of learners in the future and everything will be affected by this portable technology since education is the foundation of all branches of sciences which turned our world to better place for living.

And all the traditional methods will be soon replaced by mobile-based methods and technologies and no more trace of the old previous methods will be left in educational world as you can see nowadays that their role is diminishing and fading away gradually.

\section{REFERENCES}

[1] Amit K., Soni. (2015). Choosing the right e-learning methods: factors and elements. https://elearningindustry.com/choosingright-elearning-methods-factors-elements(accessed 24/05/2015).

[2] Al-Ahmadi, Ahlam. (2013). Characteristics of mobile learning. https://www.slideshare.net/wafaa-aljehani/characteristics-ofmobile-learning (accessed 06/04/2013).

[3] Chang, C. K., \& Hsu, C.K. (2011). A mobile-assisted synchronously collaborative translation-annotation system for English as a foreign language (EFL) reading comprehension. Computer assisted language learning, 24, 155-180.

[4] Chen, I-J., \& Chang, C.C. (2011). Content presentation modes in mobile listening tasks: English proficiency as a moderator. Computer Assisted Language learning, 24, 451-470.

[5] Chinnery, G. M. (2006). Emerging technologies, going to the MALL: Mobile assisted/language Learning. Language Learning \& Technology, 10, 9-16.

[6] Fallahkhair, S., Pemberton, L., \& Griffiths, R. (2007) Development of a cross-platform ubiquitous language learning service via mobile phone and interactive television. Journal of computer assisted Learning, 23, 321-325.

[7] Green, Sarah (2016). Re-evaluating classroom technology: The changing landscape of student engagement. https://elearningindustry.com/re-evaluating-classroom-technology-changing-landscape-student-engagement(accessed 27/11/2015).

[8] Huang, Y.M., Huang, Y.M., Huang, S.H., \& Lin, Y.T. (2012). A ubiquitous English vocabulary learning system: evidence of active/passive attitudes vs. usefulness/ease-of-use. Computers \& Education, 58, 273-282.

[9] Joseph, S., \&Uther, M. (2009). Mobile devices for language learning: Multimedia approach. Research and Practice in Technology Enhanced Learning, 4, 7-32.

[10] Klopfer E., \& Squire K. (2008) Environmental detectives-the development of an augmented reality platform for environmental simulations. Educational Technology Research \& Development, 56, 203-228.

[11] Kukulska-Hulme, A., \& Shield, L. (2008). An overview of mobile assisted language learning: From content delivery to supported collaboration and interaction. ReCALL,20, 271-289.

[12] Kukulska-Hulme, A. (2012). Language learning defined by time and place: A framework for next generation designs. In E. Diaz-Vera, Javier(ed). Left to my own devices: Learner autonomy and Mobile Assisted Language Learning. Innovation and leadership in English language teaching, 6(pp. 1-13). UK: Emerald group publishing Limited.

[13] Norton, Joanna (2014). How students can use mobiles to learn English? https://www.britishcouncil.org/voicesmagazine/teaching-tips-how-students-can-use-mobiles-to-learn-english(accessed 19/05/2014).

[14] Rahimi, M., \& Hosseini, F. (2011). The impact of computer-based activities on Iranian high-school students' attitudes towards computer-assisted language leaning. Procedia Computer Science, 3, 183-190.

[15] Rhalmi, Mohammed. (2009). Communicative language teaching (The communicative approach) $\mathrm{http} / / / \mathrm{www}$.myenglishpages.com/blog/communicative-language-teaching-communicative-approach/(accessed 18/05/2017).

[16] Rosell-Aguilar, F. (2007). Top of the pods-in search of podcasting "pedagogy" for language learning, Computer Assisted Language Learning, 20, 471-492.

[17] Savignon, Sandra J. (2000) "Communicative languages teach". In Byram, Michael. Routledge Encyclopedia of Language Teaching and Learning. London: Routledge. pp. 125-129.

[18] Seward, Zachary M. (2013). The first mobile phone call was made 40 years ago today. https://www.theatlantic.com/technology/archive/2013/04/the-first-mobile-phone-call-was-made-40-years-ago-today/274611/ (accessed 03/04/2013).

[19] Sharples, M. (ed) (2006). Big issues in mobile learning. Report of a workshop by the Kaleidoscope Network of Excellence Mobile Learning Initiative. UK: University of Nottingham.

[20] Squire, K, \&Dikkers, S. (2012). Amplifications of learning: Use of mobile media devices among youth. Convergence: The International Journal of Research into New Media Technologies, 18, 445-464.

[21] Squire, K., Jan, M., \& Mathews, J. (2007). The design and use of simulation computer games in education. In B.E. Shelton ad D.A. Wiley (eds.), The design and use of simulation computer games in education (pp. 264-296). Rotterdam, the Netherlands: Sense Publishers.

[22] Thornton, P., \& Houser, C. (2005). Using mobile phones in English education in Japan, Journal of Computer Assisted Learning, $21,217-228$

[23] Traxler, J. (2005) Mobile learning: It's here, but what is it? Interactions, 25. https://warwick.ac.uk/services/ldc/resource/interactions/issues/issue25/ (accesed 28/05/2005).

[24] Trifanova, A., \&Ronchetti, M. (2003). Where is mobile learning going? Proceedings of the E-learn Conference, 1795-1801. https://www.researchgate.net/publication/228598447_Where_is_mobile_learning_going(accessed 01/01/2003). 
Mohammad Mahdi Mobinizad was born in Mashhad City, Iran on $27^{\text {th }}$ of May, 1983. He has a BA degree in English language translation from Payame Noor University in Mashhad, Khorasane-e-Razavi Province, Iran. He also holds an MA degree in English language teaching from Payame Noor University in Dubai, UAE He finished his BA degree in 2005 and his MA degree in 2017. He is also holding a BEC: Vantage Certificate in Business English from Cambridge University

He has a six-year background experience as a SALES MANAGER in Maqsad International General Trading LLC in Dubai, UAE. He is currently an ENGLISH LANGUAGE, LITERATURE AND IELTS

TEACHER in Towheed Iranian School in Dubai with a background experience of 6 years in Teaching English. He has also conducted a research on "The use of mobile technology in learning English language on Iranian students" that he presented the said paper in the First International Conference on New Trends in English Language Teaching and Testing in Dubai, UAE on August $24^{\text {th }}, 2017$. He also attended the $16^{\text {th }}$ ELTA Serbia International Conference in Belgrade and contributed with a paper presentation on May 11-12, 2018.

$\mathrm{He}$ is currently a member of International Association of Teachers of English as a Foreign Language and his IATEFL Member ID is 30941 . 